\title{
O Sagrado e o Pensamento: o percurso filosófico-fenomenológico de Klaus Hemmerle
}

\author{
Marcio Luiz Fernandes* \\ Cleiton Costa de Santana**
}

\section{Resumo}

Qual pensar para o sagrado? Como pensar sagrado de modo que este seja sagrado ao pensamento? A partir dessas perguntas percorremos a fenomenologia do sagrado de Klaus Hemmerle, o qual nos leva a indagar as modalidades do pensar e a identificar qual o modo de pensar é capaz de captar, sem dispor, compreender sem aferrar, reconhecer sem conhecer em sua totalidade o sagrado. No percurso proposto por Hemmerle uma nova modalidade de pensamento se desvela: o verdankendes Denken. A partir de então falamos de pensamento que reconhece e acolhe a manifestação do sagrado; de pensamento que é devedor ao sagrado da possibilidade de pensá-lo enquanto tal. O presente artigo propõe uma leitura da obra "Das Heilige und das Denken: zur philosophischem phänomenologie des heiligen", do fisólofo e teólogo alemão Klaus Hemmerle, obra que se apresenta como um grande aporte para as Ciências da Religião e para a Teologia como apropriação crítica do pensamento pós-metafísico.

Palavras-chave: Klaus Hemmerle, Fenomenologia do Sagrado, o sagrado e o pensamento

\section{The Sacred and the Thought: Klaus Hemmerle philosophical and phenomenological approach}

\footnotetext{
Abstract

Wich is the thinking to the sacred? How to think the sacred so that it is sacred to thought? From these questions, we go through the phenomenology of the sacred of

* Possui graduação em Teologia pelo Studium Theologicum, Pós-doutor em Psicologia pela Universidade de São Paulo - USP. Professor adjunto no Programa de Pós Graduação em Teologia da Pontifícia Universidade Católica do Paraná - PUCPR. http://lattes.cnpq. br/3227207808620072

** Possui graduação em Sociologia pela Universidade de Brasília - UnB, doutorando em Teologia pela Pontifícia Universidade Católica do Paraná - PUCPR. http://lattes.cnpq. br/9618102219587047
} 


\section{Marcio Luiz. Fernandes}

\section{Cleiton Costa de Santana}

Klaus Hemmerle, which leads us to inquire about the modalities of thinking and to identify which way of thinking is capable of capturing, without retaining, understanding without grasping, recognizing without knowing in its entirety the sacred.

In the course proposed by Hemmerle, a new way of thinking unfolds: verdankendes Denke. From then on we talk about the thinking that recognizes and welcomes the manifestation of the sacred; the thinking that is indebted to the sacred for the possibility of thinking it as such.

This article suggests a reading of the work "Das Heilige und das Denken: zur philosophischem phanomenologiedes heiligen", by the German philosopher and theologian Klaus Hemmerle, a work that presents itself as a great contribution to the sciences of Religion and to Theology as a critical appropriation of post-metaphysical thinking.

Key-words: Klaus Hemmerle, Phenomenology of the Sacred, Sacred and Thought

\section{Lo sagrado y el pensamiento: el camino filosófico- fenomenológico de Klaus Hemmerle}

\section{Resumen}

¿Qué pensar para lo sagrado? ¿Cómo pensar sagrado para que sea sagrado para el pensamiento? A partir de estas preguntas, pasamos por la fenomenología de lo sagrado de Klaus Hemmerle, lo que nos lleva a preguntarnos las formas de pensar e identificar qué forma de pensar es capaz de capturar, sin disponer, comprender sin comprender, reconocer sin conocer en su totalidad el sagrado. En el curso propuesto por Hemmerle, se desarrolla una nueva forma de pensar: verdankendes Denken. A partir de entonces, hablamos sobre el pensamiento que reconoce y acoge la manifestación de lo sagrado; de pensamiento que está en deuda con lo sagrado por la posibilidad de pensarlo como tal. Este artículo propone una lectura del trabajo «Das Heilige und das Denken: zur philosophischem phänomenologie des heiligen», del fisiólogo y teólogo alemán Klaus Hemmerle, un trabajo que se presenta como una gran contribución a las Ciencias de la Religión y a la Teología como una apropiación crítica del pensamiento postmetafísico. Palabras clave: Klaus Hemmerle, Fenomenología de lo sagrado, lo sagrado y el pensamiento.

\section{Introdução}

O século XX nos deixou como herança um patrimônio intelectual com vertentes e desenvolvimentos ainda pouco explorados. O campo da filosofia da religião esconde ainda nomes pouco conhecidos, um deles é Klaus Hemmerle. Filósofo, teólogo, bispo católico, três facetas que nos fazem intuir o caráter poliédrico dessa figura intelectual, bem como nos aponta, imediatamente, para um aspecto peculiar do seu pensamento: um pensamento limiar, entre a teologia e a filosofia.

O caráter intelectual de Klaus Hemmerle é forjado na Universidade de Freiburg, na Alemanha dos anos 1950, onde frequentou os cursos de filosofia da religião por vias do doutorado que realizou sob a orientação de Bernhard Welte, cujo pensamento inspira toda a obra de Hemmerle, mas onde também atuou na 
cátedra de Filosofia da Religião entre os anos de 1972 e 1975, quando foi nomeado bispo de Aquisgrana, o que o obrigou a deixar o encargo na Universidade. Hemmerle faz parte do rico e intenso debate no campo da filosofia da religião estabelecido em Freiburg, à qual confluem nomes como Husserl, Heidegger, Otto, Welte, e a influência de pensadores como Edith Stein, Scheler, Franz Rosenzweig e Schelling, um ambiente cultural muito bem descrito no trabalho Pbänomenologie und Theologie im Gespräch: Impulse von Bernhard Welte und Klaus Hemmerle, ao qual remetemos para uma reconstrução mais detalhada do pensamento do autor.

Welte introduziu Hemmerle à fenomenologia de Edmund Husserl e à análise existencial de Martin Heidegger, pensadores com os quais o autor teve um permanente confronto intelectual, embora mais acentuado com Heidegger. Segundo Hagemann, o encontro com a fenomenologia será um marco para Hemmerle, não só no seu modo de pensar, mas de ver as pessoas e as coisas (HAGEMANN, 2012, p. 354). Do método fenomenológico ele assimila a epoché como escuta atenta e cada encontro pessoal, cada leitura filosófica como um modo de entrar em relação a partir do permitir que o outro manifeste o seu pensar. Na linha de Heidegger, nosso autor vai buscar um novo acesso ao Ser e na escola de pensamento do seu orientador, se confrontou seja com a abordagem filosófica de Heidegger seja com a de Karl Jaspers. Destes, Hemmerle assimilou a ideia de existência como Gegeben-Sein, Selbst-Sein, Mit-Sein, que indica a existência como não como um dado, mas como um dom que nos interpela, onde a Selbst-Sein, a identidade pessoal, adquire em Hemmerle um significado que o afasta definitivamente de Heidegger, pois no primeiro entra uma dimensão comunitária que o levará a apontar a reciprocidade relacional como fundamento da existência (DE MARCO, 2012a, p. 373).

Hemmerle estava convencido do fim da metafísica e apreende a fenomenologia na acepção que lhe dá Heidegger em o Ser e o Tempo, o que o conduzirá à busca de uma nova ontologia (HÜNERMANN, 1996, p. 61). A convicção acerca do fim da metafísica não o afasta, antes, o aproxima dos grandes nomes da teologia e filosofia cristãs. Hemmerle revisitou acuradamente o pensamento de Agostinho, Tomás de Aquino e Boaventura, perscrutando nestes as intuições ontológicas.

A fenomenologia para o autor era não só abordagem teorética, mas uma dimensão da vida. Buscou estabelecer diálogos a 360 graus. Fundamental para Hemmerle é o seu encontro com pensadores judeus, o que aconteceu seja a nível pessoal que intelectual. Juntamente com o rabino Ehrlich, fundou o grupo Juden und Christen para o diálogo católico-judeu. Hemmerle conheceu Buber e Levinás, o pensamento dialógico do primeiro transpassa as obras de Hemmerle. Com Levinás o relacionamento não se resumiu a um diálogo com a sua obra, mas a um contato 


\section{Marcio Luiz. Fernandes \\ Cleiton Costa de Santana}

pessoal. Dentre outros encontros, especialmente ligados ao diálogo católico-judeu, os dois presidiram juntos um simpósio teológico em 1986 em Simpelveld, nos Países Baixos. Levinás chegou a afirmar que os diálogos com Hemmerle foram o início do seu confronto com o pensamento cristão, especialmente quando ouviu de Hemmerle, pela primeira vez, falar da Eucaristia como momento presente no qual o Outro me vem ao encontro, onde o divino se dá de maneira pessoal (DE MARCO, 2012b, p. 742) ${ }^{1}$.

Ao lado das influências intelectuais, brevemente apresentadas acima, a vida e a obra de Hemmerle estão marcadas por um outro encontro. O encontro com Chiara Lubich e o carisma da Unidade, ocorrido no ano de 1958. Eram os anos que antecediam o Concílio Vaticano II e dentre as originais iniciativas que encontramos no período, está o surgimento de um carisma e a fundação de um movimento laical, liderado por uma jovem mulher. Trata-se do Movimento dos Focolares, ao qual Hemmerle aderiu desde o primeiro encontro com Chiara Lubich, a qual o considerou, mais tarde, co-fundador do Movimento. As intuições místicas e carismáticas de Lubich serão o substrato sempre presente na obra Hemmerle, mas sobretudo, é de onde desenvolve a intuição do acesso fenomenológico-existencial ao sagrado, do qual nos ocupamos a seguir, propondo uma leitura da obra Das Heilige und das Denken: zur philosophischem phänomenologie des heiligen, ainda sem tradução para o português.

\section{A fenomenologia do sagrado de Hemmerle}

O que significa fenomenologia filosófica do sagrado? Com essa pergunta Klaus Hemmerle inicia um percurso de investigação fenomenológica que tem como contexto e substrato a rica tradição filosófica da Universidade de Freiburg, à qual Hemmerle esteve ligado primeiro como aluno, depois, como catedrático de Filosofia da Religião, onde ressoava fortemente a voz de mestres como Husserl e Heidegger, mas também a peculiar fenomenologia da religião de Bernhard Welte.

O tema da fenomenologia do sagrado é caro a Hemmerle e à escola de pensamento à qual estava ligado. Uma referência importante é a obra de Rudolf Otto, que teve grande impacto na pesquisa filosófica de Hemmerle, de tal modo que o seu trabalho mais importante nesse tema traz "o sagrado" no título. Trata-se da obra Das Heilige und das Denken: zur philosophischem phänomenologie des heiligen,

Sobre a relação entre Hemmerle e Levinás conferir Judentum und Christentum nach Franz Rosenzweig. Ein Gespräch zwischen Emmanuel Levinas, Klaus Hemmerle, Hans Hermann Henrix, Bernhard Casper, Heinz-Jürgen Görtz und Hermann-J. Heering, in: AS V, 326-340, disponível em https://www.klaus-hemmerle.de/ 
"O sagrado e o pensamento: por uma fenomenologia filosófica do sagrado", a qual analisamos neste artigo e da qual individuamos alguns aspectos do inovador aporte de Hemmerle à fenomenologia da religião.

A obra Das Heilige und das Denken (O sagrado e o pensamento) foi publicada pela primeira vez no ano de 1966, numa coletânea de textos com dois outros autores, Bernhard Casper e Peter Hünermann, colegas de doutorado de Hemmerle. Sobre o tema do sagrado o autor retornará em outros momentos, especialmente em obras dedicadas à discussão do pensamento de Schelling ou ao desenvolvimento da intuição filosófico-fenomenológica do seu orientador de doutorado, Welte. "O Sagrado e o pensamento", porém, é voltada a "esclarecer o que é a fenomenologia filosófica do sagrado e quais relações se criam quando o sagrado se manifesta no horizonte do pensamento" (DE MARCO, 2012c, p. 53 - tradução nossa). "Autônoma” e "original” é, segundo Valentina Gaudiano, a maneira como Hemmerle se insere num contexto acadêmico complexo e de alto nível como aquele de Freiburg, onde o autor desenvolveu uma síntese peculiar do influxo dos já citados autores no âmbito das pesquisas filosóficas da religião, o que "pode explicar a fadiga da pesquisa de termos e expressões que exprimam melhor o percurso que Hemmerle faz e convida a fazer para apreender o sagrado" (GAUDIANO, 2018, p. 60 - tradução nossa).

O texto de Hemmerle se apresenta como tentativa de elaboração de uma nova síntese para a filosofia da religião. A linguagem utilizada pelo autor é aquela típica de quem está procurando saídas, ensaiando um novo modo de pensar, que seja capaz de revelar o dado da experiência num percurso teorético exigente. Para isso forja novos termos, cria neologismos, indaga a mesma realidade a partir de ângulos diferentes, resgata termos já consagrados e lhes imprime um novo significado. É assim que ele se apropria criticamente de certas categorias de Otto, como numinoso, fascinans e tremendum, mas não se atém a estas. De fato, o numinoso em Hemmerle é concebido como um sentimento religioso dentre outros, já não presente lá onde o avanço do domínio da técnica reduziu a capacidade humana de colher o aspecto maravilhoso (fascinans) dos fenômenos. Ele indica que o numinoso é sem dúvidas vestígio do sagrado, de modo que se o pensamento se fixa nesse vestígio pode colher algo do fenômeno. É, porém, bem consciente de que esse vago sentimento de temor religioso não é universalmente presente, por isso mesmo reconhece que no exílio histórico do numinoso, onde os vestígios do sagrado não são evidentes, a abertura filosófica para o pensamento acerca do ser (a ontologia) é possibilidade epocal de encontro com o sagrado.

Assumindo a tarefa histórica de abrir novas vias para a filosofia da religião e para a teologia, Hemmerle dialoga com o contexto prevalentemente secular do 


\section{Marcio Luiz. Fernandes \\ Cleiton Costa de Santana}

seu tempo. Ele sabe da necessidade de repensar a relação do ser humano com o transcendente em termos mais existenciais que metafísicos. Se aventura, assim, a iniciar esse programa repensando a relação entre o sagrado e o pensamento, que o leva a desvelar a relação entre o sagrado e o ser, a qual se declina na relação entre o ser e o ente. Para o autor, onde o pensamento sobre o ser é colocado e se torna uma questão a ser afrontada pela filosofia, dá-se ali a possibilidade histórico-existencial de encontrar o sagrado.

O caminho para o ser é, para Hemmerle, o caminho para o sagrado. E no acolher o manifestar-se do ser nos vários modos com que historicamente este se apresenta, o pensamento localiza, no presente tempo histórico, algo que está além do ser, que com este não se confunde nem está em contradição, mas nele se esconde para revelar-se a um pensamento que, esquecido de si, encontra-o e se deixa tocar, tornando-se, assim, testemunha de uma relação historicamente existente. Aquele que testemunha o faz narrando o evento, descrevendo para outrem (para um Tu) a experiência de encontro com um outro, ocorrida num dado lugar e contexto histórico, mas apreendida somente por um pensamento memorial, modalidade esta que está no centro da fenomenologia do autor.

O desafio de uma ciência da religião de caráter fenomenológico é aquele de pensar o sagrado não a partir de conceitos a este impostos, mas a partir do sagrado mesmo, da forma como este se manifesta ao pensamento. Indagar o sagrado a partir do âmbito do sagrado significa, porém, realizar uma operação teorética que manifesta os limites epistemológicos das disciplinas que se ocupam dos estudos da religião. E limite, aqui, tem a dupla valência de barreira e confim. É nesta zona limítrofe do pensamento que Klaus Hemmerle se move e nos instiga a ousar indagar o sagrado a partir dele mesmo, numa investigação que exige o repensar a nossa usual abordagem ao sagrado e, ao mesmo tempo, indagar o que é o pensamento, deslocando assim a direção investigativa para o lugar epistemológico que é o encontro entre sagrado e pensamento.

A pergunta sobre o sagrado traz consigo a questão do lugar onde o encontro entre sagrado e pensamento acontece. Esse lugar não pode ser outro, na tradição fenomenológica, senão o pensamento. Mas somente um pensamento que seja capaz de distinguir aquilo que por si se mostra (a coisa mesma) e aquilo que simplesmente é concebido no pensamento, é um seu produto (um cogitatum), é capaz de captar o fenômeno "sagrado". Por essa razão, o primeiro passo da investigação hemmerliana é questionar o pensamento. Qual pensamento é capaz de voltar-se para o fenômeno e captá-lo no realismo da coisa mesma? Para Klaus Hemmerle: 
O pensar é verdadeiro somente quando se mede com a lei da essência imposta pela coisa, quando certamente como pensamento na sua luminosidade e por si mesmo, se leva ao lugar no qual a coisa é capaz de surgir na sua peculiaridade (HEMMERLE, 2018, p. 65 - tradução nossa) ${ }^{2}$.

Não se trata, pois, simplesmente de pensar o sagrado como uma possibilidade ao pensamento, trata-se, antes, de pensar o sagrado de modo que este seja sagrado ao pensamento. A Incipit quaestio posta por Hemmerle, a qual repropomos neste trabalho, é esta: Como pensar o sagrado de modo que este seja sagrado ao pensamento? Vê-se aqui o projeto fenomenológico levado a cabo, ou seja, a exigência de "voltar às coisas mesmas", onde se faz necessária uma abordagem que deixe que a coisa se mostre completamente ao pensamento como ela é em si mesma, pois como afirma De Marco, "se a fenomenologia do sagrado quisesse fixar os cânones do manifestar-se deste último, o sagrado não seria mais como tal, mas se tornaria projeção do pensamento"3(DE MARCO, 2012c, p. 376 - tradução nossa).

Pode, então, o sagrado se mostrar como sagrado e ser apreendido como sagrado ao pensamento? Responder afirmativamente, como faz o autor, significa dizer que o pensamento admite, acolhe e aceita esse atributo (o ser sagrado) daquilo que se mostra. O percurso de Hemmerle desemboca, assim, num lugar epistemológico onde o pensar se torna experiência do sagrado.

Indicar os resultados de uma investigação fenomenológica não é tarefa fácil, pois, como afirma Ales Bello,

tais análises deveriam ser seguidas, para que se possa reconhecê-las como válidas, em suas passagens e desenvolvimentos internos. Aceitar destas somente os seus resultados pode nos levar à objeção de superficialidade ou pressuposição. Essa é a razão pela qual falar de fenomenologia é completamente diferente de conduzir uma análise fenomenológica [...] (ALES BELLO, 2003, p. 189 - tradução nossa) ${ }^{4}$.

2 Il pensare è vero solo quando si misura con la legge d'essenza imposta dalla cosa, quando certamente come pensiero nella sua luminosità per sé stesso, si porta nel luogo in cui la cosa è in grado di sorgere nella sua peculiarità.

3 "Se la fenomenologia del sacro volesse fissare i canoni del suo manifestarsi, il sacro non sarebbe più tale, divenendo proiezione del pensiero".

4 Non è agevole indicare i risultati di tale indagine, come in generale non lo è per tutte le analisi fenomenologiche, perché, in quanto analisi, debbono essere seguite nel loro svolgimento per saggiarne la validità; accettare solo i risultati può far incorrere nella obiezione di superficialità o presupposizione. Questa è la ragione per cui parlare di fenomenologia è del tutto diverso dal condurre un'analisi fenomenologica, come si è già più volte ricordato. 


\section{Marcio Luiz. Fernandes \\ Cleiton Costa de Santana}

Indicamos o itinerário de pensamento empregado por Hemmerle na sua análise, procurando esquematizar aquilo que emerge da sua pesquisa, sem pretender ser exaustivo, mas preservando a possibilidade de que a partir das pistas dadas, o leitor realize, a seu critério, um percurso semelhante.

A pesquisa fenomenológica do sagrado se embate já de início com um problema epistemológico a resolver: o que se entende por sagrado? A resposta fenomenológica parte da indicação, tanto sintética quanto instigante, que sagrado é aquilo que se mostra como tal. Isso significa que a investigação que se inicia deve impor-se a condição de deixar a coisa ser, deixar que essa se mostre como ela é. Em palavras aplicadas ao sagrado, trata-se de não o definir conceitualmente antes do seu mostrar-se ao pensamento. Não se trata, portanto, de pensar o sagrado a partir de um esquema pré-definido, nem de pensá-lo como um conceito, pois, "o postulado fundamental da fenomenologia é não impor condições àquilo que se manifesta: é preciso desenvolver uma outra modalidade de abordagem ao sagrado, na qual o pensamento se abandona e se deixa ferir" (DE MARCO, 2012c, p. 54 - tradução nossa) ${ }^{5}$.

O passo inicial de Hemmerle é a operação fenomenológica de voltar-se para a coisa mesma, passando antes pela epoché como método que permite distinguir a coisa pensada do pensamento acerca do objeto (cogitatum), para que se possa colher o mostrar-se da coisa em si e, ao mesmo tempo, individuar o próprio pensamento como lugar onde o objeto se mostra. Somente em tal distinção rigorosa o pensamento emerge em sua luminosidade, uma vez feita a operação de deixar de lado tudo o que sabe, todas as classificações, ideias e juízos, numa espécie de purificação e ascese que revela ao pensamento sua própria essência. Tal purificação, feita por meio da epochè, é um revestir-se de humildade, um colocar-se à escuta para aprender sempre e de novo do outro e da coisa que se manifesta, para que esta possa se dar livremente ao pensamento.

O caminho de Hemmerle procede com o indagar o pensamento, pois a questão aberta é antes de mais nada questão ao pensamento. O autor indica que:

O pensar é necessariamente remetido a si mesmo: deve encontrar em si mesmo um indício que, enquanto pensar, o conduza a algo como o sagrado e, ainda enquanto pensar, encontrar um traço em si mesmo que provenha de algo sagrado (HEMMERLE, 2018, p. 67-69 - tradução nossa) ${ }^{6}$.

5 Il postulato fondamentale della fenomenologia è non imporre condizioni a ciò che si manifesta: è necessario sviluppare un'altra modalità di accostarsi al sacro, in cui il pensiero si abbandona e si lascia ferire.

6 Il pensare è necessariamente rimandato a sé stesso: deve trovare in sé stesso un indizio che, in quanto pensare, lo conduca a qualcosa come il sacro e sempre in sé stesso, trovare una traccia che in esso, in quanto pensare, provenga da qualcosa di sacro. 
O pensar é atividade que mira "penetrar e explicar" todas as coisas, ligando-as e assimilando-as a si como um seu "pensado". Aquilo que o pensar pensa é o seu pensado, mas é pensado como algo que é, ou seja, o pensamento considera aquilo que pensa (o seu pensado) como sendo aquilo que foi pensado. Com isso temos que o pensamento não pensa em algo somente como um seu conteúdo, um meramente pensado, mas o pensa como algo existente. Hemmerle chega a afirmar que "só o não simplesmente pensado é realmente pensado", com isso ele está a indicar que ao indagar o pensamento encontramos sempre no pensar uma referência ao ser das coisas. Daqui o autor extrai algo importante, que os conteúdos do pensamento "se referem sempre àquilo que é enquanto um ir além do puro ter sido pensado" (HEMMERLE, 2018, p. 73 - tradução nossa).

Se por um lado o pensamento captura todas as coisas, as transpassa no seu desejo de tudo saber, na sua irrenunciável referência ao ser das coisas há algo que sempre lhe escapa e que lhe permite sempre colocar-se uma nova questão: é realmente assim como penso? Tal questão representa mais um passo da fenomenologia do sagrado para o autor. Numa acurada e articulada reflexão, Hemmerle conclui que o pensamento é capaz de dobrar-se sobre si mesmo num encadear-se de perguntas que o empurra para além de si mesmo.

Este irrenunciável reenvio ao Ser leva o pensamento ao saber-se sempre faltante daquilo que é. Mas não só a isso. No pensamento, dois aspectos se cruzam na afirmação de que algo é: que o pensamento é capaz de submeter algo a si de maneira soberana, isto é, o seu pensado; e que tal pensado, justamente porque é e enquanto é, supera e precede o pensamento. Hemmerle chama isso de batalha de Jacó entre o pensamento e o ser, da qual o pensamento sai assinalado com o marco comemorativo, a marca do ser em si. No voltar-se para si reflexivo do pensamento, este descobre, na sua autorrealização reflexiva, a si mesmo e, sobretudo, o Ser como seu a priori.

O mesmo percurso reflexivo, porém, o pensamento não é capaz de realizar quando indaga sobre o sagrado, o que leva Klaus Hemmerle a propor a questão (que é o passo seguinte da sua investigação): quando, então, é que o pensamento se compreende como voltado para o sagrado? Quando se dá conta de que não é capaz de submeter a si o fenômeno que lhe está diante numa modalidade de pensamento que "dispõe-determina aquilo que é e que quer", fenômeno este que lhe causa maravilha e estupor, que o toca profundamente e que ao mesmo tempo não se impõe por força de violência ou proibições, mas em virtude do seu status e essência (HEMMERLE, 2018, p. 77). O pensamento então sabe-se voltado para algo sagrado no momento em que, tomado pelo estupor, exclama "isto é sagrado!". 


\section{Marcio Luiz. Fernandes \\ Cleiton Costa de Santana}

E no exclamar é!, um paradoxo se estabelece, que reenvia o filósofo a perguntar-se novamente acerca da modalidade de pensamento que, sem submeter a si aquilo que pensa, é capaz de dizer que é algo que o deixa sem palavras.

Note-se que neste passo o sagrado não é identificado com o numinoso, também não é o tremendum. Não é a proibição violenta que causa estupor e admiração, mas a essência do fenômeno que se manifesta. A admiração, aqui, é associada à gênese do pensamento filosófico tal qual preconizado na filosofia grega e o numinoso é tão somente um dado da experiência. O autor escava, então, o sentido da expressão "isto é sagrado", indicando que naquele é se dá um encontro entre o ser e o ente, que inaugura uma nova temporalização (pois algo aconteceu) na concretude da existência. Para o autor, a experiência do sagrado não conhece nada de atemporal, não conhece nenhum dado prévio à experiência e toda forma de experiência do sagrado é tal sempre e solo no horizonte histórico da manifestação do ser.

Há, porém, a barreira de uma espécie de pensamento, comum mesmo ao filósofo, que é aquele autoconfiante na própria capacidade de compreender a totalidade do pensado, se apropriar de todas as coisas por meio da própria conceitualização. Interpretando Hemmerle, Viviana De Marco afirma que "diante do pensamento que a si tudo sujeita, o sagrado não se dobra mas se retrai: é tanto mais sagrado, ou seja, realidade incomparável e incomensurável, quanto mais escapa à tentativa do pensamento de o capturar" (DE MARCO, 2012c, p. 54 - tradução nossa) $)^{7}$.

Retomando o postulado fenomenológico de "retorno às coisas mesmas", De Marco mostra que Hemmerle supõe a existência de modalidades de pensamento que não impõem condições ao fenômeno, mas que reconhece que é o fenômeno, neste caso o sagrado, a impor-se ao pensamento. Segundo a autora, o pensador indica que:

No lugar do pensamento que captura conceitualmente (fassendes) se desenvolve um pensamento que se abre ao sagrado e o deixa ser (lassendes Denken). É um pensamento que acolhe com gratidão o surgir do sagrado (verdankendes Denken): o gesto não é o agarrar como uma mão que tudo quer conter em si, mas é aquele de acolher como uma mão que se abre (DE MARCO, 2012c, p. 54 - tradução nossa) $)^{8}$

\footnotetext{
Davanti al pensiero che aferra, il sacro non si piega ma si ritrae: è tanto più sacro, cioè realtà incomparabile e incommensurabile, quanto più sfugge al pensiero afferrante.

$8 \quad \mathrm{Al}$ posto del pensiero afferrante si sviluppa un pensiero che accoglie con gratitudine il sorgere del sacro: il gesto non è l'afferrare come una mano che tutto vuole serrare in sé, ma è quello di accogliere come una mano che si apre.
} 
Enuncia-se, então, na filosofia fenomenológica do sagrado que Hemmerle elabora, uma modalidade de pensamento que seria capaz de manter a tensão entre o caráter indômito do sagrado e a força dominadora e restritiva do pensamento que não pode renunciar a seu reenvio ao Ser. Trata-se do verdankendes Denken, isto é, o pensamento que sabe-se devedor a outrem e é por isso grato, por reconhecer-se originado e não origem do pensar.

Certamente o pensamento não pode renunciar a indicar o seu pensado com um é, mas exatamente neste ponto o pensamento torna-se a si mesmo luminoso, porque ao enunciar que o sagrado é algo, o pensamento se depara com o próprio limite, pois está defronte a algo que não se submete a seu poder; e no entanto se mostra ao pensamento. Trata-se de um encontro, aquilo que se dá entre o pensamento e o sagrado, no qual o pensamento experimenta o falimento de não poder dizer nada além de "aqui encontrei algo de sagrado"; e fazendo assim, confessando a sua impotência, o pensamento cumpre o seu desígnio por identificar em si o outro de si mesmo. Hemmerle afirma que o pensamento é o contrário do sagrado porque é da essência do primeiro penetrar todas as coisas e levá-las à luminosidade desmistificante que lhe é típica. Ocorre, porém, que quando o sagrado se dá, se manifesta e toca o pensamento, o faz em correspondência à própria essência, mostra-se como é e nisto supera o pensamento que dele quer se apropriar e a este bloqueia no seu perímetro de ação. O pensamento, então, neste falimento, é na verdade idêntico a si, conhece a si mesmo no próprio limite que lhe vem imposto pelo outro. E aqui o pensamento torna-se ainda mais luminoso e colhe a evidência do fenômeno que a ele se manifesta.

$\mathrm{Na}$ luz que lhe é própria, o pensamento fiel à sua essência, pergunta, questiona o mundo e os fenômenos a partir da sua inquietude típica. Mas sabe que a pergunta ao sagrado, inevitável e certa, deve ser dirigida em maneira qualitativamente diferente. Inquirir o sagrado em modo que este continue sagrado ao pensamento é chegar ao limite do pensar, é ir até onde o pensamento pode ir como e enquanto pensamento. A partir do encontro deste com a "coisa" demandada, resta-lhe somente um sóbrio contentar-se de ter chegado à veta numa árdua subida. Ir além é entrar noutro espaço epistemológico, o espaço do crer, pois o encontro se torna adesão. Aquém dessa zona limítrofe está ao pensamento reconhecer, não tanto pôr pergunta inquisitória ao sagrado, mas preservando-se como pensamento, interpelar o Outro com um apelativo.

A pesquisa filosófica de Hemmerle nos conduz aqui ao limite, à fronteira epistemológica entre filosofia e teologia. E desvela, ao mesmo tempo, a precariedade do pensamento para pensar o sagrado mantendo a sua sacralidade diante do 


\section{Marcio Luiz. Fernandes \\ Cleiton Costa de Santana}

pensamento. Isso porque necessariamente tal sacralidade vela o pensar e o envolve na nebulosidade do evento de revelação, o sagrado manifesta ao pensamento seu ser completamente outro, apartado, indisponível. E por tal indisponibilidade o pensamento não faz que exclamar a santidade do terreno no qual ora se encontra. Na perspectiva de Hemmerle, onde identificamos traços da mística apofática de Mestre Eckhart, diante do sagrado o pensamento silencia e se encontra em dificuldades para manter a característica de tudo perscrutar e submeter a si. Mas em perfeita unidade e identidade com a própria essência, o pensamento descobre, segundo Hemmerle, que tem, mesmo diante do sagrado, "direito" de perguntar, ainda que seja um interpelar apelativo. Um perguntar que catapulta o pensamento fora de si, na direção da sua origem, onde encontra o Outro por excelência. O pensamento se sabe, assim, devedor à sua origem, pois não pode ter origem em si mesmo, mas somente de um outro.

O percurso filosófico de Hemmerle, que ora trilhamos, nos leva a afrontar a questão da concepção do sagrado como projeção do pensamento, que é um aspecto presente na história da filosofia da religião, especialmente na sua vertente que se liga a Ludwig Feuerbach. Sem elaborar uma resposta formal a tal questão, Hemmerle dá duas indicações de resposta que são resultantes do percurso fenomenológico realizado até aqui.

A primeira é que o pensamento que captura, agarra o fenômeno e o submete a si pode cair na tentação de projetar-se sobre o sagrado. O pensamento pode, então, conceber um "sagrado" e atribuir-lhe atributos vários, delimitando-o e descrevendo-o com a formalização de um conceito. Fica evidente, porém, que aqui não estamos diante de algo sagrado, mas de uma "profanação". Um tal sagrado, domado pelo pensamento, não resiste à investigação fenomenológica e não resiste, sobretudo, ao percurso retrospectivo que leva o pensamento à própria origem. Não resiste, também, à questão inicial do trabalho de Hemmerle, pois tal sagrado não seria sagrado ao pensamento, mas seria mero pensado.

O segundo aspecto é que o percurso filosófico guiado por Hemmerle localiza o lugar de manifestação do sagrado no pensamento. Este descobre a sua origem e se reconhece devedor. Sabe que somente como pensamento em débito e grato é capaz de acolher o manifestar-se do sagrado. Mas sobretudo, sabe que quando o sagrado se manifesta o pensamento mesmo sofre uma mudança qualitativa, é tomado pela maravilha e pelo estupor, é enfim, tocado e ferido. Torna-se, na concepção de Hemmerle, testemunha de um evento.

A reflexão acerca da origem do pensamento pode dar a impressão de que a proposta hemmerliana seja idealista, ou, ao menos, que o encontro com o sagrado 
seja resultado de uma busca filosófica solipsista. É exatamente o contrário disso! Em Hemmerle o percurso reflexivo do pensamento sobre si e sobre a própria origem serve, antes de mais nada, ao próprio pensamento, para que este adquira a liberdade de acolher sem capturar e restringir, numa espécie de alargamento da capacidade perceptiva em relação aos fenômenos. O itinerário reflexivo retrospectivo que atinge a origem do pensar e o transforma, o converte num pensar verdankendes, devedor e grato, não é que o passo fundamental que capacita o pensamento a colher a manifestação do sagrado.

Tal manifestação se dá, porém, no presente das vivências do sujeito, o que evidencia o caráter histórico e múltiplo dos modos de dar-se do sagrado, donde se desdobra dois outros filões do pensamento de Hemmerle, a ontologia (que já é ensaiada nas páginas de Das Heilige und das Denken) e a hermenêutica, os quais foram desenvolvidos mais tarde nas Thesen zu einer Trinitarischen Ontologie (Teses de Ontologia Trinitária). A fenomenologia é pensada como prelúdio a esses dois aspectos filosóficos. O envio à origem do pensamento é preparativo, é tensão ao futuro incerto e impreciso da possibilidade de manifestação do sagrado na história. Há, como se percebe, uma passagem de caráter temporal na filosofia de Hemmerle, uma projeção para o futuro, onde o conhecer a origem do pensamento faz as vezes de um anúncio de possibilidade vindoura. Mas é no presente que a possibilidade se realiza. E é quando se está já no terreno do sagrado que se reconhece (porque capacitado para tal) a sua presença, como Jacó que no relato bíblico exclama "este lugar é sagrado e eu não sabia!" (cf. Gen 28, 16).

Tocado pelo sagrado, o pensamento não é mais o mesmo. A experiência feita conduz o pensar a um novo perquirir a si mesmo. Estamos na última passagem proposta pela fenomenologia de Hemmerle. Aqui a indagação é "o que é que me aconteceu?". O pensamento percebe uma mudança qualitativa na realidade apreendida ${ }^{9}$, houve uma interrupção temporal que o leva a pensar sobre o ocorrido. A pergunta “o que foi que me aconteceu?", feita pelo sujeito tomado pelo estupor do evento, desvela não uma subjetividade solitária do ser, mas uma existência acompanhada por um Outro que se dá e que faz do pensamento um pensar dirigido a algo, que no ato de recordar presentifica esse algo.

O pensamento tocado pelo sagrado se torna memorial. É Pensamento memorial (andenken Denken), que conserva a experiência da manifestação do sagrado e a torna não recordação do passado, mas evento do presente. "O pensamento mesmo é recordação (An-denken) e monumento (Denk-Mal) porque sabe que tudo

$9 \quad$ Nesse aspecto a fenomenologia de Micea Eliade com suas distinções entre sagrado e profano são um grande contributo para a compreensão deste traço da filosofia de Hemmerle. 
se transformou, algo lhe aconteceu!" (HEMMERLE, 2018, p. 133 - tradução nossa $)^{10}$. Para que se compreenda a relação memória/presente, o autor traz o exemplo do templo. Para ele um lugar não é sagrado porque ali aconteceu algo, num tempo pretérito, é sagrado porque ali acontece algo, alguma coisa se faz presente naquele espaço, que marca uma descontinuidade físico-temporal com outros lugares. Se assim não fosse, não haveria diferença alguma entre templo e museu. E, no entanto, a diferença existe e pode ser fenomenologicamente apreendida.

No museu quanto no templo a vivência do sujeito é marcada pela experiência mediada por imagens, sons, palavras, etc. Tanto um quanto outro introduzem o sujeito numa nova dimensão espaço-temporal, diferente da cotidiana, mas a relação com a memória é radicalmente diferente na vivência do templo em relação àquela do museu. Neste último, a memória está para recordação de acontecimentos passados, o marco está para a celebração do feito, a história está para o concatenar-se factual de causas e efeitos. No templo, a memória é presentificação, o marco é hierofania e a história não é só relembrada e contada em suas passagens trágicas e gloriosas, mas por meio do rito, por exemplo, a história é revivida e representada.

Segundo Kampff, o termo Andenken, também presente na obra de Heidegger, significa lembrança fiel, algo que remete igualmente a ânimo e a coração, a um voltar-se fielmente destes à origem doada por outrem (KAMPFF, 2017, p. 80). É aqui que o ponto de chegada da pesquisa de Hemmerle, no desvendar uma modalidade de pensamento segundo a qual o pensar luminoso é capaz de colher o manifestar-se do sagrado, de modo que este seja reconhecido como sagrado pelo pensamento.

O pensamento completa o seu êxodo, sai do terreno de si, das próprias certezas, da vontade de capturar e submeter as coisas a si (fassendes Denken); vai além de si, se descobre pensamento que deixa ser as coisas (lassendes Denken), porque sabe que não pode renunciar sua referência ao ser; Volta-se para si, busca a sua origem, descobre-se a si mesmo no seu limite e se capacita como pensamento grato e devedor à sua origem (verdankendes Denken) a receber a visita do sagrado. Somente o verdankendes Denken, de acordo com Hemmerle, é pensamento capaz de entrar na terra santa do sagrado e colher a sua manifestação na existência concreta do ente. Uma vez que o sagrado lhe vem ao encontro, o pensamento,

\footnotetext{
10 Aqui há um jogo de palavras no texto de Hemmerle que é difícil de traduzir para o português. Reporto aqui o texto original em alemão e o texto em italiano: "Das Denken selbst ist An-denken und Denk-Mal des Heiligen, weil es weiß: Alles ist anders geworden, es ist ihm etwas geschehen!" "Il pensiero stesso è ri-cordo e marchio-commemorativo del sacro perché esso sa: tutto è diventato diverso, gli è successo qualcosa!".
} 
ferido por este, sofre uma nova mudança. Torna-se memorial (Andenken), registro, testemunha do sagrado. O que Hemmerle quer nos dizer com isso? Gaudiano assim resume o percurso hemmerliano:

[Hemmerle] está afirmando que somente no ato de recordar o fato que tenha se apresentado a nós, este torna-se novamente presente e em tal presentificação se faz presença que nos revela a nossa proveniência; eis então que o pensamento se reconhece devedor e, portanto, assume uma nova atitude em relação ao sagrado, aquela de reconhecimento (verdankendes Denken). (GAUDIANO, 2018, p. 191 - tradução nossa) ${ }^{11}$

A mudança ocorrida no pensamento é aquela que definitivamente substitui o é do afirmar que agarra e circunscreve a coisa no seu pensado para um está, que localiza o sagrado num é aqui presente afirmativo e maravilhado do pensamento. $\mathrm{O}$ Andenken que sucede temporalmente o verdankendes Denken é justamente a localização de um lugar, que é marco, testemunha, monumento de memória.

No texto de Hemmerle, a passagem entre as modalidades de pensamento é um percurso filosófico árduo, feito com uma escrita repleta de jogos de palavras e em uma circularidade ascendente em espiral, onde o autor desdobra e refaz questões com o intuito de garantir o rigor teorético e explorar todas as possibilidades de respostas e objeções. Tal percurso culmina, como já acenado, no localizar o sagrado no pensamento, que nos leva a pensar o sagrado numa região epistemológica limítrofe, entre a teologia e a filosofia.

Hemmerle era um crente. E a sua fenomenologia, embora filosófica, cruza o limiar entre as disciplinas, não para promover um mix, nem por falta de rigor, mas para promover um novo diálogo e síntese na busca da verdade. No seu pensamento, Verdade e Testemunho estão articulados de maneira indissociável e tal articulação é, para ele, uma exortação ao confronto dialógico entre as disciplinas, no qual o testemunho tem papel fundamental. Esse testemunho é, sempre, o testemunho de alguém, de um sujeito histórico no qual se enredam os nós das vivências que o constituem em seu pensar e agir. Se esse sujeito faz filosofia, não o faz independentemente daquilo que crê ou não crê, nem sua pesquisa filosófica é completamente separada do contexto cultural e religioso em que vive. Hemmerle estava inserido no contexto cultural de Freiburg, uma das cidades-berço

11 Sta affermando che solo nell'atto di ricordadre il fatto che il sacro si sia a noi presentato questo diventa nuovamente presente e in tale presentificazione si fa presenza che ci rivela la nostra provenienza; ecco allora che il pensiero si riconosce debitore e quindi assume un nuovo atteggiamento verso il sacro, quello della riconoscenza (verdankendes Denken). 
da fenomenologia. Naquele círculo cultural não foram raros os casos daqueles que se tornaram crentes. Hemmerle, porém, não é um convertido. É, antes, um interpelado pelo desafio que a filosofia de Martin Heidegger apresenta à filosofia de matriz cristã, onde Klaus Hemmerle se encontra.

Resta sempre um limiar, que é a liberdade de adesão. Alguém pode testemunhar a possibilidade do encontro sem aderir, existencialmente, àquilo que encontra. Ou pode fazê-lo segundo o timbre da adesão, ou seja, como quem crê. O que não é possível é conceber uma disjunção entre vida e pensamento. Por isso Hemmerle termina seu percurso admitindo que as últimas palavras de sua reflexão fenomenológico-filosófica sobre o sagrado o orientam para um suplicar adorante, porque não é mais capaz de colher nenhum outro mostrar-se da coisa e de nenhuma outra palavra própria, mas somente de uma palavra que soa como "Mostra-nos a tua face e seremos salvos!" (S1 80, 3).

\section{O tema da luminosidade do fenômeno}

Um ponto fundamental para a compreensão da fenomenologia do sagrado aqui apresentada é o aspecto da luminosidade, com frequência evocada como aspecto peculiarmente importante para a apreensão do fenômeno do sagrado. A ideia de luminosidade do pensamento e do fenômeno é cara a Hemmerle. Ele a assimila e reinterpreta a partir das indicações de Heidegger, especialmente do $\$ 7$ de Ser e Tempo. Ao traçar a origem e precisar o sentido do termo fenomenologia, Heidegger destrincha o significado originário de fenômeno, que em grego está associado à ideia de "trazer para luz", indicando a luminosidade do dia como o meio por excelência no qual um fenômeno se mostra, revela a si mesmo como é. Daí a sua sintética e eloquente afirmação de que "Os fenômenos constituem, pois, a totalidade do que está à luz do dia ou se pode pôr à luz, o que os gregos identificavam, algumas vezes, simplesmente com: (os entes), a totalidade de tudo que é" (HEIDEGGER, 2005, p. 58). Heidegger precisa, ainda, a acepção que faz do termo fenômeno distanciando-o do significado de aparecer, parecer e aparência. A ideia de fenômeno enquanto "o que se revela, o que se mostra a si mesmo"

Quando o sagrado se manifesta não se mostra como algo que não é. Tal manifestação é manifestação do fenômeno, da coisa que se mostra na luminosidade do dia. Essa luminosidade do fenômeno pode, porém, ofuscar-se se o fenômeno não for recebido por um pensamento que seja a si mesmo luminoso, isto é, se uma luminosidade meridiana não estiver presente no pensamento que reflete sobre si e se sabe, também, fenômeno. Assim, um tal pensamento pode realizar 
a radicalidade da epochè, isto é, torna-se capaz de se autodistinguir daquilo que é o fenômeno que se manifesta.

Em Hemmerle, porém, o adjetivo luminoso não se refere somente à clareza conceitual ou à evidenciação da distinção dos múltiplos aspectos do pensamento. $\mathrm{O}$ autor joga com o sentido mesmo da palavra para indicar o uso peculiar que a acepção de luz e luminosidade têm no âmbito do sagrado, pois estas estão entre suas características. A luminosidade, assim, está também no sagrado. Isso significa que, para o autor, a luminosidade é parte da manifestação do fenômeno ao pensamento, o que implica que esta é uma propriedade que envolve o manifestar-se de um para outro, estando presente em ambos. A luminosidade do pensamento se faz ver no mostrar-se do sagrado, o que indica uma espécie de simultaneidade existente entre ambos os fenômenos.

Carmelo Meazza, em diálogo com o autor, especifica que essa luminosidade a que Hemmerle se refere não emana do objeto. Não vem, igualmente, do sujeito, como se o pensamento fosse uma espécie de farol que clareia e delimita os contornos do objeto, apreendido pela noética do pensamento. Não é, portanto, uma espécie de animação noético-noemática do objeto. Para Meazza:

Esse "iluminar-se" do pensamento em uma luminosidade que é simultânea ao mostrar-se do sagrado, desenvolve uma função essencial. Se assim não fosse, se não exercitasse a sua instância, não haveria nenhum critério de distinção entre aquilo que realmente se mostra e aquilo que é simplesmente concebido a partir de si. Sem tal luminosidade não seria possível aderir à coisa mesma, não conseguiríamos preservar a evidência do mostrar-se contra um fatal idealismo no qual a autoevidência do pensar se sobrepõe à realidade do mostrar-se (MEAZZA, 2019, p. 95 - tradução nossa) ${ }^{12}$.

Coligado ao tema da luminosidade está o da datidade. Objeto da investigação hemmerliana é o sagrado em sua manifestação, no seu dar-se ao pensamento. Tudo aquilo que se mostra ao pensamento, dirá Hemmerle, é para este objeto de reflexão filosófica, onde "a identidade entre o pensar e o mostrar-se da coisa existe no pensamento graças ao mostrar-se da coisa” (HEMMERLE, 2018, p. 65

12 Questa specie di accensione del pensiero, in una luminosità che coaccade nel mostrarsi del sacro, svolge una funzione essenziale. Se non vi fosse, se non esercitasse la sua istanza, non vi sarebbe alcun criterio per distinguere tra «ciò che gli si mostra veramente e ciò che semplicemente da sé concepisce». Senza questa luminosità non si potrebbe aderire alla cosa stessa, non si riuscirebbe a preservare l'evidenza del mo-strarsi da un fatale idealismo in cui l'autoevidenza del pensare si sovrappone al reale del mostrarsi. 


\section{Marcio Luiz. Fernandes \\ Cleiton Costa de Santana}

- tradução nossa) ${ }^{13}$. É o mostrar-se da coisa que desperta o pensamento em sua luminosidade, que o faz pensar. Reside nesse caráter manifesto da coisa a exigência de uma fenomenologia como método capaz de apreendê-la. Note-se, porém, que não se trata aqui de teorizar uma passividade do pensamento, ao contrário, aquilo que se mostra o faz a um pensamento que permite sua manifestação. É questão de reciprocidade relacional entre o pensamento e a coisa mesma, pois o mostrar-se da coisa é sempre um mostrar-se a, o que implica a existência de uma relação do pensamento com o seu pensado enquanto algo que se mostra, com um tu que o transcende.

O dar-se do sagrado ao pensamento é visto como dom originário, como um projetar de si para um outro. Por tal razão, o pensamento capaz de apreender é o pensamento que acolhe com gratidão, que se dispõe a aceitar a condição do dar-se da coisa.

\section{O pensamento que se reconhece devedor}

Vimos que para Hemmerle um predicado do pensamento é justamente querer penetrar a coisa pensada, submetê-la a rigorosa avaliação, dissecá-la a fim de compreender seus aspectos e transformá-los em algo pensado, ou seja, algo de algum modo assimilado ao pensamento. $\mathrm{O}$ sagrado, porém, no seu dar-se ao pensamento não permite tal operação. O pensamento é, de certo modo, anuviado e não pode exprimir-se, inicialmente, senão com uma expressão do simples dar-se conta de que está diante de algo que é sagrado.

O pensamento, assim, deve renunciar à conceituação, renunciar a tendência à afirmação de que a coisa "é". O autor indica que o pensamento constringente (fassendes Denken) é aquele que quer conter em si, com as proporias forças e capacidades, a coisa. Mas sua atividade de pretensão totalizante se embate justamente na realidade do ser da coisa, que lhe escapa. O pensamento que captura conceitualmente a coisa o faz afirmando que algo é. No afirmar que é, o pensamento sabe que essa afirmação guarda uma diferença com a coisa em si, a qual permanece fora da esfera da consciência. Ou seja, na definição que o pensamento faz daquilo que é por ele pensado, abre-se uma situação de ambiguidade, visto que o pensamento não pode renunciar ao dizer é em relação àquilo que pensa e no entanto sabe que aquilo que é supera o puro pensado.

Se abre assim, para o pensamento, um horizonte autorreflexivo que o leva à origem do pensar, à descoberta de que não é fundado em si, mas recebe-se do

13 L'identità tra pensare e mostrar-si della cosa è nel pensiero grazie al mostrar-si della cosa. 
fundamento como dom da alteridade, que o faz tornar-se um verdankendes Denken. Nesse termo se enovelam dois aspectos, o da dívida e o da gratidão, típicos de quem recebe um dom ao qual não é capaz de retribuir, a não ser com a própria coerência e adesão ao dom recebido. A língua portuguesa guarda, nesse aspecto, um dado peculiar, pois o termo corrente obrigado resume em si esses dois aspectos. É seja a gratidão, seja o sentimento de obrigação, constrição e dívida. É no dizer "obrigado" que o pensamento se torna hábil a captar o sagrado que se manifesta.

Será sempre constrito, o pensamento, a operar no nível da linguagem a sua referência ao ser das coisas, dos entes. Mas não o fará como antes, pois a sua situação existencial mudou. É agora pensamento fiel à memória (andenken Denken) do evento que a ele se manifestou. Memória que não se resume a recordação, ato evocativo do ser. Mas que, para Hemmerle, é monumento, isto é, custódia do sagrado, lugar onde este se faz presente. Notamos aqui semelhanças e diferenças com o pensamento de Heidegger, e as encontramos na reflexão pós-metafísica da relação entre Deus e o pensamento empreendidas por ambos os pensadores.

Para ambos, a relação entre Deus e o pensamento passa pela questão do ser, por uma ontologia. Mas as maiores semelhanças encontramos na abordagem de ambos ao pensamento. Para eles a questão posta ao sagrado é, contemporaneamente, questão posta ao pensamento, onde a busca pelo sagrado revela o pensamento a si mesmo. Sagrado, ser e pensamento estão, assim, ligados, relacionam-se numa espécie de pertencer comum que Kampff, interpretando o pensamento de Heidegger, assim o descreve:

Trata-se de um comum-pertencer que se dá na medida em que o pensar do homem se abre em direção ao ser e forma com ele uma relação que o plenifica, e, nesse sentido, pensar acaba por definir o próprio ser, pois, “o reino do ser não pode ser entendido sem o co-reino do pensamento. Por outro lado, o pensar só é pensar quando iluminado pelo ser, ou seja, só é possível compreender o pensamento como um pensar próprio quando o encontramos a caminho do ser, quando o pensar responde ao chamado do ser. É por isso que na pergunta: "que é isso que nos chama a pensar?" Heidegger evoca o Andenken, que significa memória, gratidão. Porque o pensar pertence ao ser, deve ser fiel a ele, guardando em si a memória da sua própria essência (KAMPFF, 2017, p. 84).

O distanciamento de Hemmerle em relação a Heidegger se dá, entre outros aspectos, na já acenada questão da presentificação efetuada pela memória e, mais ainda, porque em Hemmerle a pergunta sobre o sagrado não se liga somente à 


\section{Marcio Luiz. Fernandes \\ Cleiton Costa de Santana}

questão do ser, mas especificamente à questão sobre o ser humano concreto, sobre a sua existência em cada época histórica, pois o pensar é pensar de um ser humano na especificidade da sua existência (GAUDIANO, 2018, p. 188).

A fenomenologia do sagrado de Hemmerle nos oferece, portanto, como exigência e possibilidade, um novo pensar. $\mathrm{O}$ autor se encontrava no bojo do caldeirão cultural que marcaram o século XX e que deixaram de herança às ciências da religião novos instrumentos metodológicos e novas questões a serem afrontadas. $\mathrm{O}$ aporte de Hemmerle é não somente indicar um método (que para ele é a fenomenologia), mas advertir para a necessidade de uma mudança radical na forma de pensar, tanto marcada ainda pela determinação de certezas infundidas pelo domínio da técnica. Pensar com Hemmerle requer capacidade de estupor e maravilha, requer aprender a pensar e converter-se a um novo pensamento. Humilde, mas consciente das próprias capacidades. E por isso mesmo iluminado por uma luz na qual é possível compreender o inefável.

\section{Aportes da fenomenologia do sagrado de Klaus Hemmerle para a teologia}

Como autor, Klaus Hemmerle marca uma retomada do tema ontológico na teologia católica, imprimindo-lhe um distintivo: o caráter trinitário do seu pensamento. No trabalho que analisamos esse distintivo não é ainda aparente em toda a sua magnitude, o que acontecerá somente dez anos mais tarde com a publicação das Thesen zu einer trinitarischen Ontologie, em 1976. Compreender, porém, a abordagem fenomenológica do autor na sua investigação acerca do sagrado é fundamental para acessar a sua produção filosófica e teológica, seja porque o ensaio "Das Heilige und das Denken" é o primeiro trabalho publicado depois do doutoramento em filosofia da religião, seja porque esse mesmo trabalho é um marco da recepção crítica da filosofia heideggeriana no âmbito católico.

Piero Coda, atualmente o maior intérprete e divulgador da filosofia e da teologia hemmerliana, notadamente por quanto diz respeito à vertente ontológica dos seus estudos, afirma que Hemmerle foi capaz de uma operação filosófico-teológica de grande importância. Coda afirma que, estando imerso no contesto fenomenológico e filosófico do seu tempo, o autor foi capaz de fazer frutificar a reabertura ao fenômeno do sagrado e o caráter pós-metafísico dessa abertura nos círculos intelectuais germânicos, notadamente na escola de Freiburg, em um novo modo de pensar acerca do Sagrado, do Ser e do ente. E o fez recuperando as mais originárias intuições do pensamento cristão de Agostinho, Tomás e Boa- 
ventura, conjugando assim teologia e filosofia em uma nova perspectiva ontológica (CODA, 2018, p. 7).

À parte a sua grande contribuição para uma nova ontologia, apontada por autores como Lubomir Zak e Massimiliano Zupi como programática para uma teologia que queira entrar em diálogo com a filosofia do nosso tempo (ou pós-moderna, como prefere Zupi) (Zak, 1998, p. 11; ZUPI, 2017, p. 9), a particular síntese filosófica de Hemmerle na sua fenomenologia do sagrado nos aporta ao menos dois horizontes para o desenvolvimento da teologia: o caráter narrativo do pensamento memorial e a figura da testemunha como elemento chave para a investigação do sagrado.

Para o autor o pensamento grato (verdankendes Denken) não enumera (conta) (zählt) mas conta (narra) (er-zählt) aquilo que lhe aconteceu no encontro com o sagrado (HEMMERLE, 2018, p. 107-109). Sai de cena o pensamento contábil que enumera o pensado como posse do pensamento, que encadeia os conceitos segundo uma lógica de circunscrição do fenômeno a um conjunto de elaborados intelectuais e entra o pensamento narrativo, que testemunha os acontecimentos segundo a lógica da memória, que conta reconhecendo para que o outro possa conhecer e reconhecer o fenômeno do qual se faz testemunha. Em tal indicativo de narrar o fenômeno não está em jogo somente a relação entre pensamento e sagrado. Hemmerle remete a uma necessidade de repensar tempo e espaço a partir da manifestação do sagrado. De fato, o tempo narrativo inaugura uma nova temporalização no âmbito da linguagem e introduz quem escuta numa nova espacialidade.

Da compreensão hemmerliana de que o sagrado não pode ser enumerado, mas contado, deriva, também, uma indicação metodológica para o estudo do sagrado: a atenção às narrativas do dar-se do sagrado, onde quem o acolhe se torna testemunha. Ouvir, portanto, o testemunho de quem presencia o manifestar-se hierofânico é um dado primordial para uma fenomenologia filosófica do sagrado, pois possibilita a esta apreender do sujeito não uma enumeração, um elenco de características do sagrado, mas, a partir da narração, chegar à coisa mesma, passando pela escuta e acolhida do narrado no pensamento de quem escuta, sabendo que acolher e escutar, sem juízo prévio nem conceitualização apressada é epoché, portanto primeiro e fundamental passo metodológico para passar a uma modalidade de pensamento adaptada à datidade do sagrado.

Emerge aqui a figura da testemunha do evento a qual habita um lugar limítrofe entre perspectivas intelectuais distintas, a filosófica e a teológica. A testemunha pode transmutar a atitude do testemunhar na adesão do crer. Mas é a abordagem que faz dessa experiência que caracteriza o pensar daquele que adentra 
o terreno do sagrado como pensamento filosófico ou teológico. A experiência do sagrado não é, para Hemmerle, experiência de fé. Para o autor a fé nasce da adesão a uma revelação, não da busca filosófica. Esta pode encontrar a revelação e desembocar num contexto de fé, assim como a partir da revelação (de um contexto de fé), pode nascer uma filosofia que se autonomiza em relação ao contexto originário. Os limites entre cada uma das perspectivas possíveis diante do sagrado não são, pois, barreiras, mas fronteiras onde quem ingressa num novo território pode encontrar vastos e novos horizontes de pensamento.

De fato, a pergunta posta por Hemmerle leva o pensamento fenomenológico-filosófico a parar diante da manifestação do sagrado. E nisso consiste, justamente, o reconhecer a sacralidade da coisa ao pensamento. Avançar sobre a coisa como para dela apropriar-se com o pensamento, agarrar o sagrado com pretensão omnicompreensiva é, então, abandonar a postura filosófica e ultrapassar uma barreira epistemológica da disciplina. Mas é, também, dessacralizar o fenômeno transformando-o em mera coisa pensada, em cogitatum sem reenvio à coisa em si, sem referência à transcendência da coisa em relação ao pensamento. Admitindo, porém, que se possa adentrar esse terreno obscuro e nebuloso do sagrado e que se possa falar, pensar a partir do sagrado, deve-se, então, igualmente admitir que neste caso não só o limite epistemológico da filosofia é ultrapassado, como o é, também, o da teologia. A teologia só é capaz de falar a partir de uma revelação, é dali que ela toma a palavra, a partir da palavra que fora revelada.

Uma tal experiência direta do sagrado é possível somente como mística. A partir da mística se pode fazer teologia e filosofia, mas os três âmbitos de apreensão do sagrado são e restam diferentes. A mística, porém, é uma peculiar forma de testemunho da experiência do sagrado, de grande relevância para a teologia. $\mathrm{Na}$ mística a manifestação do sagrado na luminosidade do pensamento é ao grau máximo, onde é evidente que é o fenômeno mesmo a impor suas condições ao pensar. É o sagrado que irrompe, irresistivelmente, à consciência, ao pensamento e à vida psíquica do sujeito, marca-o na sua corporeidade e na sua vida social.

Hemmerle não teoriza a importância do testemunho da mística para a teologia, mas o vive em primeira pessoa. Assim como Hans Urs von Balthasar bebe da mística de Adrienne von Speyr e desenvolve em nível teológico aquilo que lhe fora comunicado em linguagem mística, de igual forma Klaus Hemmerle o faz. Este encontra na mística de Chiara Lubich o testemunho a partir se pode encontrar o sagrado. Mas como vimos, o testemunho narrado presentifica o evento e abre a quem escuta uma nova possibilidade. Assim, o autor afirma que "para poder compreender uma tal visão do ser é preciso ser. A estrada que conduz a 
uma nova ontologia é uma estrada de ser, isto é, do viver. Vê somente quem vive"14(HEMMERLE, 2014, p. 129 - tradução nossa). O acesso é sempre existencial.

A possibilidade da reflexão filosófica acerca do sagrado é dada pelo mostrar-se mesmo do sagrado ao pensamento. De certo modo, está aqui presente o clássico pensamento católico do Homo capax Dei, no entanto, o caminho percorrido por Hemmerle não é dogmático, ou seja, ele afirma a possibilidade de apreensão do sagrado pelo pensamento a partir da especulação filosófica, é certo, mas inda mais acertado é que tal afirmação vem da experiência. Ao indagar o pensamento, Hemmerle considera que neste o sagrado se faz presente e nisso um duplo movimento se apresente, do pensamento que é capaz de colher o sagrado em sua manifestação, e do sagrado, que se manifesta de forma tal que pode ser colhido pelo pensamento, embora não o seja indiscriminadamente por toda forma de pensar.

Nessa capacidade do sagrado de abrir-se ao pensamento encontramos uma característica do sagrado, qual seja, a inteligibilidade, mas também a sua capacidade adaptativa à linguagem e à compreensão humanas. Uma reflexão mais acurada percebe nesse abrir-se do sagrado à inteligência humana, traços de uma ontologia do sagrado, o qual se dá como ontologicamente constituído pela capacidade de dar-se e de se relacionar com o outro de si mesmo. De igual forma, a ontologia do ser humano, constituído na e para a relação com o outro de si em nível de paridade, mas também em nível vertical, com o Outro que é origem e horizonte da relação.

Se perscrutamos o pensamento que se põe a pergunta acerca do sagrado, nos damos conta de que o pensar sobre o sagrado e o abrir-se do sagrado ao pensamento são, necessariamente eventos contemporâneos. Isso porque se a nossa pergunta-guia for uma pergunta válida do ponto de vista filosófico (como pensar o sagrado de modo que seja sagrado ao pensamento?), não podemos conceber resposta que dê primazia temporal ao pensamento, ou seja, que o absolutize. Isso significa que uma resposta que conceba o sagrado como projeção do pensamento, como criação da mente não é uma resposta logicamente válida. Somente ao sagrado pode ser dada uma certa precedência, pois atribuir a este a primazia temporal é a única possibilidade existente para a manutenção dos polos sagrado-pensamento enquanto tais. Ocorre, porém, que a existência mesma desses polos denuncia que ao pensamento e no pensamento, a datidade de pensamento e sagrado pressupõe a contemporaneidade do manifestar-se de ambos, como anteriormente já explicitado. O sagrado não pode manifestar-se enquanto sagrado sem um pensamento que o reconheça e acolha como sagrado. O pensamento não pode pensar o sagrado,

14 Per poter comprendere tale visione dell'essere bisogna essere. La strada che conduce all'ontologia nuova è una strada dell'essere, cioè del vivere. Vede solo chi vive. 


\section{Marcio Luiz, Fernandes}

Cleiton Costa de Santana

reconhecê-lo e acolhê-lo em si, como sagrado, sem que deste não derive o ser pensado, o ser reconhecido e acolhido como sagrado.

Nessa intuição hemmerliana encontramos um dos traços da intuição mística que está no substrato do seu pensamento. Em um outro ensaio, o autor declina a simultaneidade supra referida tomando como chave de leitura o evento cristológico. "No ecce homo" - afirma Hemmerle - "acontece o ecce filosofia"15(HEMMERLE, 2018, p. 253), mas é sobretudo no grito de Jesus na cruz "meu Deus, meu Deus, por que me abandonaste?" que o autor encontra o fundamento, o sentido e o horizonte do fazer teologia, sim, mas ainda mais do fazer filosofia, do perguntar. No abandono de Jesus está a fonte do pensamento que se abandona, reconhece-se grato e devedor, mas que ousa dirigir um apelo e é, por isso, visitado pelo sagrado.

\section{Conclusão}

Para quem está imbricado nos campos da Ciência da Religião e da Teologia, pensar a relação entre o sagrado e o pensamento é uma questão inescapável do fundamento epistemológico dessas ciências. A peculiaridade do sagrado enquanto objeto por excelência dessas ciências nos interroga e nos impõe questões importantes para a manutenção do rigor das investigações num campo que se pretenda científico. Elas dizem respeito ao lugar epistemológico do pesquisador, que para o pesquisador mesmo deve ser explicitado. E, ainda, diz respeito ao objeto, à sua delimitação ou, onde entra com maior vigor o aporte de Hemmerle, à capacidade de colhermos o sagrado como este se dá em toda a sua originalidade e liberdade, sem portanto, a presunção de "delimitar" mas com a grata capacidade de indicar, testemunhar a coisa mesma, tal qual se é manifestada na luminosidade do pensamento.

O texto de Hemmerle é um convite ao exercício da capacidade narrativa das ciências da religião, para que numa linguagem nova e ousada, estas possam frequentar a fronteira epistemológica existente entre filosofia e teologia, promovendo o diálogo entre essas disciplinas e com as demais ciências. A partir de um novo pensar, as ciências da religião podem colher, em meio à cultura secular, nas indagações mais agudas e na busca de sentido presentes no nosso tempo, o manifestar-se do sagrado na peculiaridade histórica do mostrar-se contingente do ser.

\section{Referências}

BAUsenharT, G; BÖHNKE, M; LORENZ, D. (org.). Phänomenologie und Theologie im Gespräch: Impulse von Bernhard Welte und Klaus Hemmerle (2016), Verlag Herder: Freiburg, 2016.

15 Nell "ecce homo" avviene un "ecce philosophia". 
CODA, P. Prefazio. In HEMMERLE, Klaus. Un pensare ri-conoscente: scritti sulla relazione tra filosofia e teologia. Roma: Città Nuova Editrice, 2018.

CODA, P. L'itinerario e il contributo di K. Hemmerle per un "nuovo" pensiero. In HEMMERLE, Klaus. Tesi di ontologia trinitaria: per un rinnovamento del pensiero cristiano. Roma: Città Nuova Editrice, 1996.

DE MARCO, V. Amare la chiesa dell'altro come la propria: Klaus hemmerle e l'unità dei cristiani. In Nuova Umanità, $n^{\circ}$ XXXIV (2012/6) 204, pp. 739-761.

DE MARCO, V. Alla radice delle cose e dell'essere. La fenomenologia nel pensiero filosofico e Teologico di klaus hemmerle. In Nuova Umanità, $n^{\circ}$ XXXIV (2012/3) 201, pp. 371-388.

DE MARCO, V. L'esperienza di Dio nell'unità: il pensiero filosofico, teologico ed estetico di Klaus Hemmerle. Roma: Città Nuova Editrice, 2012c.

GAUDIANO, V. La sfida del sacro: cornice introdutiva a "Il sacro e il pensiero" e chiavi di lettura a "Il sacro e il pensiero". In K. HEMMERLE, Un pensare ri-conoscente: scritti sulla relazione tra filosofia e teologia (p. 59-61 e 186-195). Roma: Città Nuova Editrice, 2018.

HAGEMANN, W. Klaus Hemmerle: innamorato della Parola di Dio. In Nuova Umanità, $\mathrm{n}^{\circ}$ XXXIV (2012/3) 201, pp. 351-370.

HEIDEGGER, M. Ser e Tempo (Parte I). Tradução Márcia de Sá Cavalcante Schuback. Petrópolis: Vozes, 2005.

HEMMERLE, K. Das Heilige und das Denken. Zur philosophischen Phiinomenologie des Heiligen - Il sacro e il pensiero: per una fenomenologia filosofica del Sacro (edizione bilingue tedesco-italiano) In K. HEMMERLE, Un pensare ri-conoscente: scritti sulla relazione tra filosofia e teologia. Roma: Città Nuova Editrice, 2018.

HEMMERLE, K. Das problematische verhältnis von philosophie und theologie theologische perpektiven - Il problematico rapporto tra filosofia e teologia. Prospettive teologiche (edizione bilingue tedesco-italiano) In K. HEMMERLE, Un pensare ri-conoscente: scritti sulla relazione tra filosofia e teologia. Roma: Città Nuova Editrice, 2018.

HEMMERLE, K. Tesi di ontologia trinitaria: per un rinnovamento del pensiero cristiano. Roma: Città Nuova Editrice, 1996.

HEMMERLE, K. L'ontologia del “paradiso” '49. In Sophia VI (2014-2), p. 127-137. 2014

HUNERMANN, P. L'Altro è come me - ma Dio è come l'Altro. Caratteristiche principali del pensiero teologico di Klaus Hemmerle. In Nuova Umanità, no XVIII (1996) 1, p. 59-74.

MEAZZA, C. In dialogo con Klaus Hemmerle. Nuovo Giornale di Filosofia della Religione, p. 94-100, 2019.

KAMPFF, V. L. Heidegger e o outro pensar: uma breve leitura de Que chamamos pensar? In Análogos, 2017, n 1, pp. 76-85.

ZAK, L. Abitando la Trinità: per un rinnovamento dell'ontologia. Roma: Città Nuova Editrice, 1998.

ZUPI, M. Per un'ontologia della carne che pensi l'essere come amore: una lettura delle Thesen di Klaus Hemmerle. Roma: Associazione culturale piccola barca, 2017. 